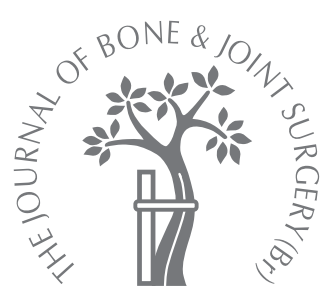

Y.-H. Kim, S.-H. Yoon, J.-S. Kim

From the Ewha Womans University College of Medicine, Seoul, Korea

= Y.-H. Kim, MD, Professor and Director

S.-H. Yoon, MD, Clinical

Fellow

J.-S. Kim, MD, Associate

Professor

The Joint Replacement Center of Korea

Ewha Womans University College of Medicine,

DongDaeMun Hospital, 70

ChongRo 6-Ga, ChongRo-Gu,

Seoul 110-783, Korea.

Correspondence should be sent to Professor Y.-H. Kim; e-mail: younghookim@ewha.ac.kr

(2)2007 British Editorial Society of Bone and Joint Surgery doi:10.1302/0301-620X.89B2. $18634 \$ 2.00$

$J$ Bone Joint Surg $[\mathrm{Br}]$ 2007;89-B:174-9.

Received 20 September 2006 Accepted 13 October 2006

\title{
Changes in the bone mineral density in the acetabulum and proximal femur after cementless total hip replacement
}

\author{
ALUMINA-ON-ALUMINA VERSUS ALUMINA-ON-POLYETHYLENE \\ ARTICULATION
}

Our aim in this prospective study was to compare the bone mineral density (BMD) around cementless acetabular and femoral components which were identical in geometry and had the same alumina modular femoral head, but differed in regard to the material of the acetabular liners (alumina ceramic or polyethylene) in 50 patients (100 hips) who had undergone bilateral simultaneous primary total hip replacement. Dual energy X-ray absorptiometry scans of the pelvis and proximal femur were obtained at one week, at one year, and annually thereafter during the five-year period of the study.

At the final follow-up, the mean BMD had increased significantly in each group in acetabular zone I of DeLee and Charnley (20\% (15\% to $26 \%), p=0.003)$, but had decreased in acetabular zone II $(24 \%(18 \%$ to $36 \%)$ in the alumina group and $25 \%(17 \%$ to $31 \%)$ in the polyethylene group, $p=0.001)$. There was an increase in the mean BMD in zone III of $2 \%$ $(0.8 \%$ to $3.2 \%)$ in the alumina group and $1 \%(0.6 \%$ to $2.2 \%)$ in the polyethylene group ( $p=0.315)$. There was a decrease in the mean BMD in the calcar region (femoral zone 7 ) of $15 \%(8 \%$ to $24 \%)$ in the alumina group and $14 \%(6 \%$ to $23 \%)$ in the polyethylene group ( $p<0.001)$. The mean bone loss in femoral zone 1 of Gruen et al was $2 \%(1.1 \%$ to $3.1 \%)$ in the alumina group and $3 \%(1.3 \%$ to $4.3 \%)$ in the polyethylene group $(p=0.03)$, and in femoral zone 6 , the mean bone loss was $15 \%(9 \%$ to $27 \%)$ in the alumina group and $14 \%$ $(11 \%$ to $29 \%)$ in the polyethylene group compared with baseline values. There was an increase in the mean BMD on the final scans in femoral zones $2(p=0.04), 3(p=0.04), 4$ $(p=0.12)$ and $5(p=0.049)$ in both groups.

There was thus no significant difference in the bone remodelling of the acetabulum and femur five years after total hip replacement in those two groups where the only difference was in the acetabular liner.

Stress shielding is an important cause of periprosthetic bone loss after total hip replacement (THR). ${ }^{1-3}$ While there are numerous reports of stress-shielding-related peri-prosthetic bone loss involving the proximal femur after THR, , ${ }^{1,4-11}$ little attention has been paid to secondary stress shielding in the peri-acetabular region. Computer simulations and a few clinical studies have found decreases in the bone mineral density (BMD) around cementless acetabular components and the proximal femur after THR using a cobalt-chrome femoral head and an ultra-high-molecularweight polyethylene (UHMWPE) acetabular liner. $^{12-14}$

An advantage of hard-bearing articulations such as alumina-on-alumina is a reduction in the production of wear debris and subsequent osteolysis. A theoretical disadvantage of these hard bearings is an increase in the periprosthetic bone resorption related to stress shielding because of the stiff material properties of the bearing surfaces.

We therefore performed a prospective, randomised study to compare the change in the peri-prosthetic BMD around cementless acetabular and femoral components which were identical in geometry and used an alumina femoral head, but differed in the material of the acetabular liners which was either alumina ceramic or UHMWPE.

\section{Patients and Methods}

The senior author (Y-HK) performed consecutive primary bilateral sequential THRs in 50 patients (100 hips) during the same anaesthetic session.

There were 38 men and 12 women with a mean age at the time of surgery of 51 years (35 to 66). The diagnosis included osteonecrosis of the femoral head in 31 patients (62 hips), osteoarthritis in 18 (36 hips) and multiple 


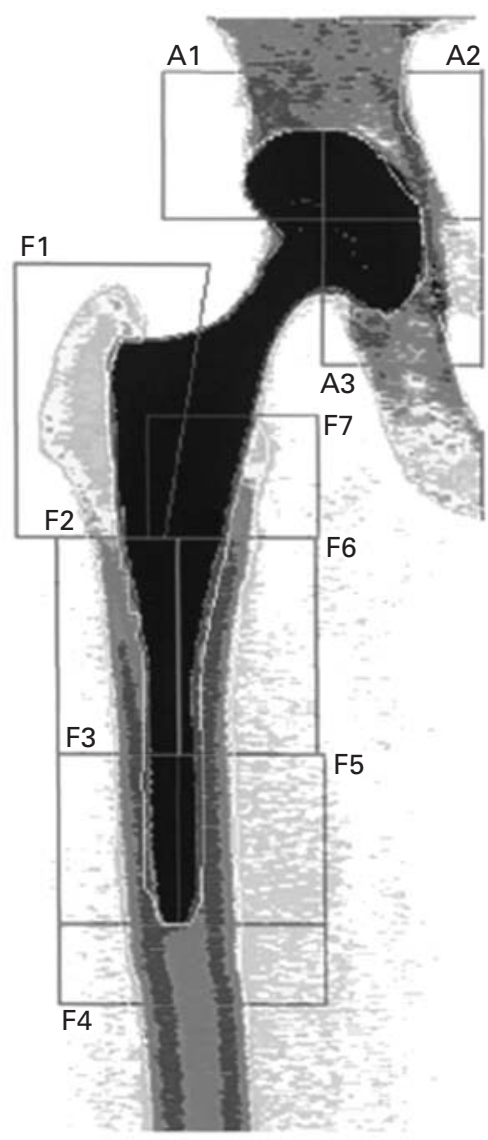

Fig. 1

A DEXA scan showing the acetabular zones of DeLee and Charnley, ${ }^{19}$ and the femoral zones of Gruen et al. ${ }^{20}$

epiphyseal dysplasia in one (2 hips). The mean follow-up was for 4.8 years (4 to 6 ).

Patients received an Immediate Post-operative Stability cementless femoral component (IPS, DePuy, Leeds, United Kingdom) with a $28 \mathrm{~mm}$ alumina ceramic femoral head. The IPS femoral component is an anatomical metaphyseal fitting titanium stem with a polished and tapered distal stem, designed to provide fixation in the metaphysis only, thereby avoiding metal-to-bone contact below this point. The proximal $30 \%$ of the stem was porous-coated with sintered titanium beads, with a mean pore size of $250 \mu \mathrm{m}$ to which a hydroxyapatite coating was applied to a thickness of $30 \mu \mathrm{m} .{ }^{15}$

A cementless Duraloc Optional acetabular component (DePuy) with an alumina ceramic liner of inner diameter $28 \mathrm{~mm}$ (alumina group) was used in one hip and a cementless Duraloc 100-series acetabular component (DePuy) with a UHMWPE liner of inner diameter $28 \mathrm{~mm}$ (polyethylene group) was used in the opposite hip. The Duraloc Optional and 100 acetabular shells were identical, with the titanium shell thicknesses increasing from $3.8 \mathrm{~mm}$ to
$11.3 \mathrm{~mm}$ with increasing diameter of the acetabular component. Loosening of the femoral component was diagnosed if there was a varus shift or progressive axial subsidence. Loosening of the acetabular component was diagnosed if there was a change in position or a continuous radiolucent line wider than $2 \mathrm{~mm}$ on both the anterior and lateral views.

Randomisation of the use of an alumina or polyethylene liner was determined from a sequential pool based on a table of random numbers. No patient was lost to follow-up, and all were included in the study which was approved by the institutional review board at our institution. All patients gave informed consent.

Dual energy X-ray absorptiometry (DEXA) scan acquisition and analysis. All patients underwent DEXA scanning of the pelvis and proximal femur using the same Hologic QDR 4500A fan-beam densitometer (Hologic Inc., Waltham, Massachusetts) and the metal-removal hip-scanning mode. They were placed in the supine position with the affected leg in slight internal rotation. The foot was attached to a positioning device to obtain reproducible rotation. ${ }^{16-18}$ The analysis software was modified in 15 hips (15\%) to increase the threshold for exclusion of metal since the preset threshold was insufficient to distinguish between the thick bone of the pelvis and the femur and the metal of the acetabular component and stem.

Pelvic scan acquisition commenced $2 \mathrm{~cm}$ below the lower border of the inferior pubic ramus, using a field width of $15 \mathrm{~cm}$. The scans were orientated so that the acetabular component lay in the centre of the field. Acquisition was continued proximally to $2 \mathrm{~cm}$ above the lower limit of the ipsilateral sacroiliac joint. Femoral scan acquisition was started approximately $2.5 \mathrm{~cm}$ distal to the tip of the femoral prosthesis, with the longitudinal axis of the shaft of the prosthesis vertical and occupying the centre of the scan field. The scan was continued proximally to $2 \mathrm{~cm}$ above the tip of the greater trochanter (Fig. 1). The first DEXA scan was made one week after surgery and served as a baseline for the subsequent scans as recommended by Kröger et al. ${ }^{1}$ Further scans were obtained at one year and yearly thereafter during the five-year period of the study. The pelvic and femoral scans were analysed independently by a single observer (S-ML) who was not involved in the clinical care of the patients. The acetabular scans were examined by creating regions of interest according to the zones of DeLee and Charnley ${ }^{19}$ and the femoral scans were studied using the zones of Gruen, McNeice and Amstutz. ${ }^{20}$ The acetabular regions of interest were created by bisecting the centre of the component with a horizontal and vertical line. The superior and inferior borders of the regions were then defined by horizontal lines placed 30 pixel lines superiorly and inferiorly to the upper and lower limits of the component, respectively. The medial and lateral boundaries were defined by vertical lines placed 15 pixels outside their respective limits. The femoral regions of interest were defined by dividing the proximal femur into seven Gruen 


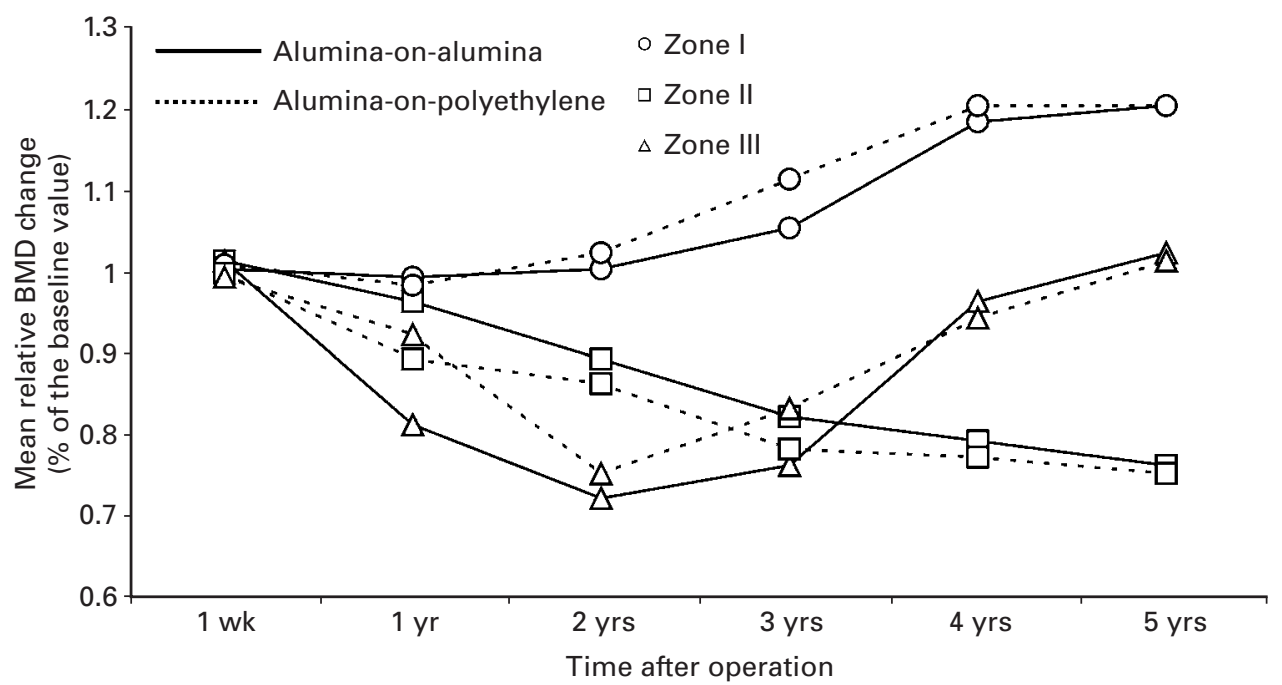

Fig. 2

Relative changes in the bone mineral density (BMD) of the three DeLee and Charnley ${ }^{19}$ acetabular zones plotted against time.

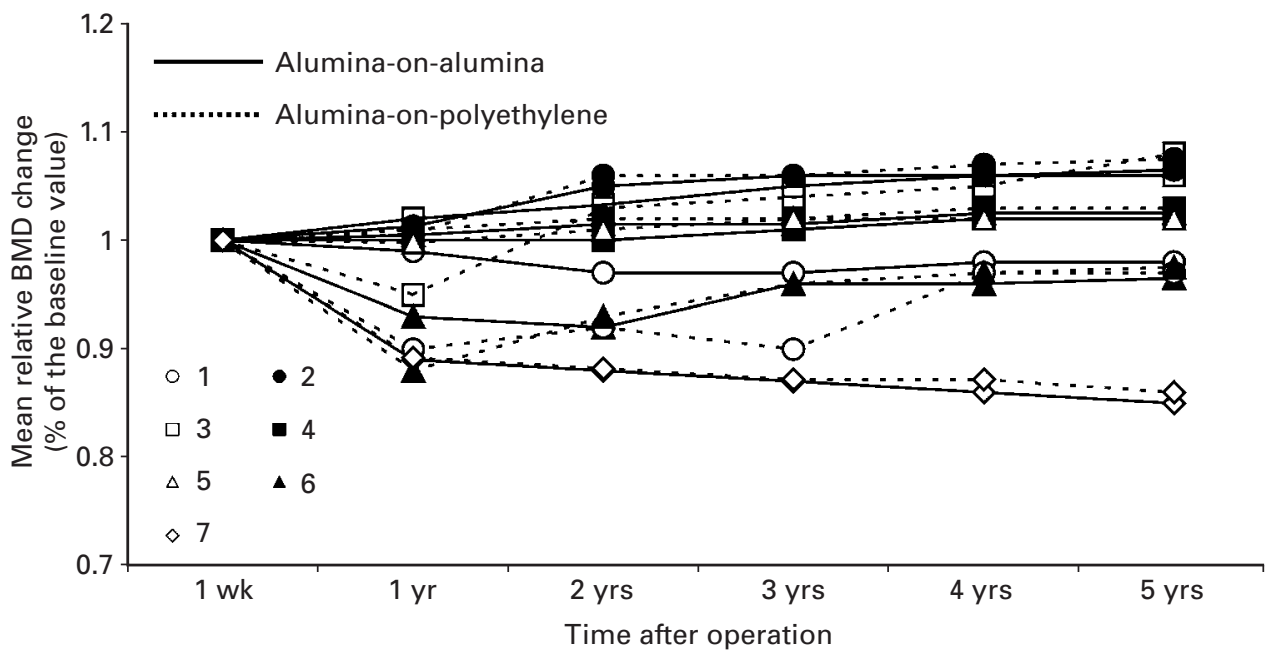

Fig. 3

Relative changes in the bone mineral density (BMD) of the seven femoral zones of Gruen et $\mathrm{a}^{20}$ plotted against time.

zones $^{20}$ according to the guidelines in the Hologic user manual (Fig. 1). ${ }^{21}$

At the five-year end-point, we analysed the effects of age, gender, body mass index (BMI) and underlying diagnosis on the changes in BMD around the acetabular and the femoral components. The patients were divided into two age groups: those under 50 years of age and those over 50 years. The BMI was classified as normal $\left(<25 \mathrm{~kg} / \mathrm{m}^{2}\right)$, and overweight or obese $\left(\geq 25 \mathrm{~kg} / \mathrm{m}^{2}\right)$. Patients were also categorised according to gender and underlying diagnosis. We assessed clinical success by calculating the Harris hip score. $^{22}$

Statistical analysis. Analysis of variance, with fixed factors and the random patient factor, was calculated for each region separately. Subsequently, post-hoc comparisons between time points were performed according to Tukey's 
Table I. Mean bone mineral density $\left(\mathrm{g} / \mathrm{cm}^{2}\right)$ of the acetabulum and proximal femur according to gender

\begin{tabular}{|c|c|c|c|c|c|c|}
\hline \multirow[b]{2}{*}{ Zones } & \multicolumn{2}{|l|}{ Male } & \multicolumn{2}{|l|}{ Female } & \multicolumn{2}{|l|}{ p-value } \\
\hline & 1 week & 5 years & 1 week & 5 years & 1 week & 5 years \\
\hline \multicolumn{7}{|c|}{ Acetabulum } \\
\hline I & 1.445 & 1.590 & 1.364 & 1.500 & 0.297 & 0.955 \\
\hline II & 1.140 & 1.000 & 1.065 & 0.935 & 0.304 & 0.194 \\
\hline III & 1.247 & 1.256 & 1.006 & 1.014 & $0.010^{*}$ & $0.001^{*}$ \\
\hline \multicolumn{7}{|l|}{ Femur } \\
\hline 1 & 0.711 & 0.702 & 0.649 & 0.641 & 0.150 & 0.486 \\
\hline 2 & 1.304 & 1.343 & 1.112 & 1.151 & $0.035^{*}$ & $0.026^{*}$ \\
\hline 3 & 1.736 & 1.797 & 1.470 & 1.522 & $0.002^{*}$ & $0.001^{*}$ \\
\hline 4 & 1.884 & 1.908 & 1.509 & 1.528 & $0.000^{*}$ & $0.000^{*}$ \\
\hline 5 & 1.800 & 1.823 & 1.532 & 1.551 & $0.000^{*}$ & $0.000^{*}$ \\
\hline 6 & 1.487 & 1.468 & 1.407 & 1.389 & 0.211 & 0.430 \\
\hline 7 & 1.035 & 0.960 & 1.128 & 1.043 & 0.377 & 0.794 \\
\hline
\end{tabular}

Table II. Mean bone mineral density $\left(\mathrm{g} / \mathrm{cm}^{2}\right)$ of the acetabulum and proximal femur according to age

\begin{tabular}{|c|c|c|c|c|c|c|}
\hline \multirow[b]{2}{*}{ Zones } & \multicolumn{2}{|c|}{$<50$ years } & \multicolumn{2}{|c|}{$\geq \mathbf{5 0}$ years } & \multicolumn{2}{|l|}{ p-value } \\
\hline & 1 week & 5 years & 1 week & 5 years & 1 week & 5 years \\
\hline \multicolumn{7}{|c|}{ Acetabulum } \\
\hline I & 1.363 & 1.499 & 1.424 & 1.566 & 0.399 & 0.809 \\
\hline II & 1.152 & 1.011 & 1.080 & 0.948 & 0.262 & 0.084 \\
\hline III & 1.236 & 1.245 & 1.100 & 1.108 & 0.154 & 0.429 \\
\hline \multicolumn{7}{|l|}{ Femur } \\
\hline 1 & 0.701 & 0.692 & 0.680 & 0.672 & 0.650 & 0.141 \\
\hline 2 & 1.377 & 1.425 & 1.410 & 1.459 & 0.838 & 0.838 \\
\hline 3 & 1.585 & 1.640 & 1.698 & 1.757 & 0.177 & 0.978 \\
\hline 4 & 1.800 & 1.823 & 1.715 & 1.736 & 0.411 & 0.586 \\
\hline 5 & 1.741 & 1.768 & 1.678 & 1.699 & 0.326 & 0.549 \\
\hline 6 & 1.519 & 1.500 & 1.395 & 1.378 & $0.050^{*}$ & $0.049^{*}$ \\
\hline 7 & 1.196 & 1.109 & 0.920 & 0.085 & $0.002^{*}$ & $0.002^{*}$ \\
\hline
\end{tabular}

HSD (honestly significant differences) range test. ${ }^{23}$ No further adjustment for multiplicity was performed, the main results being supported by very small $p$-values. A p-value $\leq 0.05$ was considered to indicate statistical significance.

\section{Results}

The mean pre-operative Harris hip score was 46 points ( 7 to 55 ) and increased to a mean of 93 points ( 85 to 100 ) at the final follow-up. All the acetabular and femoral components were stable with bone ingrowth on the latest radiographs.

The results of DEXA scanning were plotted as the percentage change in BMD over time relative to the immediate post-operative value for each patient. The mean values of the percentage change in BMD for all the areas were also plotted for both groups of patients at 1,2, 3, 4 and 5 years, in order to observe the trend in gain or loss of the BMD for both groups (Fig. 2).

In comparison to the baseline values, there was a mean loss of $1 \%(0.7 \%$ to $1.6 \%)$ in the alumina group and $2 \%$ $(1.4 \%$ to $2.8 \%)$ in the polyethylene group at acetabular zone I one year after surgery $(\mathrm{p}=0.493)$. At five years, there was a mean gain of $20 \%(15 \%$ to $26 \%)$ in each group com- pared with the baseline values ( $p=0.003)$, but the difference in BMD between the groups was not significant $(\mathrm{p}=0.851)$ (Fig. 2).

Compared with baseline values, there was a progressive decrease in the BMD in acetabular zone II in both groups. The difference was not significant during the first two years, $(\mathrm{p}=0.187)$ but achieved significance in both groups between three and five years $(\mathrm{p}<0.001)$. At the final follow-up the mean decrease in BMD was $24 \%(18 \%$ to $36 \%)$ in the alumina group and $25 \%(17 \%$ to $31 \%)$ in the polyethylene group $(\mathrm{p}=0.001)$ but there was no significant difference $(\mathrm{p}=0.165)$ in the mean BMD between the two groups (Fig. 2).

When compared with baseline values, the mean BMD in acetabular zone III progressively underwent a decrease in both groups for the first three years $(24 \%$ (17\% to $32 \%)$ in the alumina group and $17 \%(8 \%$ to $28 \%))$ in the polyethylene group), but this loss was restored to baseline levels after four years in both groups. The final BMD showed a mean increase of $2 \%(0.8 \%$ to $3.2 \%)$ in the alumina group and of $1 \%(0.6 \%$ to $2.2 \%)$ in the polyethylene group, which was not significantly different from the baseline value of each group $(p=0.315)$. There was no significant 
Table III. Mean bone mineral density $\left(\mathrm{g} / \mathrm{cm}^{2}\right)$ of the acetabulum and proximal femur according to body mass index $\left(\mathrm{kg} / \mathrm{m}^{2}\right)$

\begin{tabular}{|c|c|c|c|c|c|c|}
\hline \multirow[b]{2}{*}{ Zones } & \multicolumn{2}{|l|}{$<25$} & \multicolumn{2}{|l|}{$\geq \mathbf{2 5}$} & \multicolumn{2}{|l|}{$p$-value } \\
\hline & 1 week & 5 years & 1 week & 5 years & 1 week & 5 years \\
\hline \multicolumn{7}{|c|}{ Acetabulum } \\
\hline 1 & 1.355 & 1.491 & 1.519 & 1.671 & $0.017^{*}$ & $0.045^{*}$ \\
\hline II & 1.108 & 0.972 & 1.136 & 1.000 & 0.730 & 0.820 \\
\hline III & 1.198 & 1.207 & 1.047 & 1.055 & 0.114 & 0.313 \\
\hline \multicolumn{7}{|l|}{ Femur } \\
\hline 1 & 0.669 & 0.661 & 0.762 & 0.752 & $0.035^{*}$ & $0.047^{*}$ \\
\hline 2 & 1.191 & 1.233 & 1.402 & 1.451 & 0.069 & 0.452 \\
\hline 3 & 1.600 & 1.656 & 1.798 & 1.861 & 0.052 & 0.444 \\
\hline 4 & 1.592 & 1.6119 & 1.692 & 1.713 & 0.367 & 0.367 \\
\hline 5 & 1.693 & 1.714 & 1.759 & 1.781 & 0.379 & 0.618 \\
\hline 6 & 1.417 & 1.399 & 1.609 & 1.589 & $0.009^{*}$ & $0.007^{*}$ \\
\hline 7 & 1.053 & 0.977 & 1.112 & 1.031 & 0.580 & 0.149 \\
\hline
\end{tabular}

Table IV. Mean bone mineral density $\left(\mathrm{g} / \mathrm{cm}^{2}\right)$ of the acetabulum and proximal femur according to diagnosis

\begin{tabular}{|c|c|c|c|c|c|c|}
\hline \multirow[b]{2}{*}{ Zones } & \multicolumn{2}{|c|}{ Osteonecrosis } & \multicolumn{2}{|c|}{ Osteoarthritis } & \multicolumn{2}{|l|}{ p-value } \\
\hline & 1 week & 5 years & 1 week & 5 years & 1 week & 5 years \\
\hline \multicolumn{7}{|c|}{ Acetabulum } \\
\hline I & 1.571 & 1.598 & 1.362 & 1.728 & $0.006^{*}$ & 0.105 \\
\hline II & 1.179 & 1.035 & 1.109 & 0.973 & 0.533 & 0.525 \\
\hline III & 1.281 & 1.291 & 1.257 & 1.266 & 0.514 & 0.0634 \\
\hline \multicolumn{7}{|l|}{ Femur } \\
\hline 1 & 0.771 & 0.700 & 0.665 & 0.655 & 0.070 & 0.704 \\
\hline 2 & 1.438 & 1.488 & 1.102 & 1.282 & $0.001^{*}$ & 0.0276 \\
\hline 3 & 1.820 & 1.884 & 1.533 & 1.728 & $0.001^{*}$ & 0.818 \\
\hline 4 & 1.859 & 1.882 & 1.567 & 1.728 & $0.001^{*}$ & 0.361 \\
\hline 5 & 1.823 & 1.869 & 1.581 & 1.741 & $0.000^{*}$ & 0.709 \\
\hline 6 & 1.566 & 1.546 & 1.388 & 1.470 & $0.009^{*}$ & 0.170 \\
\hline 7 & 1.110 & 1.030 & 1.042 & 0.954 & 0.552 & 0.301 \\
\hline
\end{tabular}

difference $(p=0.315)$ in mean BMD between the two groups (Fig. 2).

In femoral zone 1 five years after surgery there was a mean bone loss of $2 \%(1.1 \%$ to $3.1 \%)$ in the alumina group and of $3 \%(1.3 \%$ to $4.3 \%)$ in the polyethylene group when compared with the baseline values $(p=0.03)$. In femoral zone 7 (the calcar region) there was a mean bone loss of $15 \%(8 \%$ to $24 \%)$ in the alumina group and of $14 \%$ $(6 \%$ to $23 \%)$ in the polyethylene group compared with the baseline value $(\mathrm{p}<0.001)$. In both groups, the mean BMD increased by $6.9 \%(6 \%$ to $8 \%)$ in femoral zones $2,3,4$ and 5 (Fig. 3). There were no significant differences $(p=0.12)$ in the mean BMD between the groups. In femoral zone 6 five years after surgery, there was a mean bone loss of $15 \%(9 \%$ to $27 \%$ ) in the alumina group and of $14 \%(11 \%$ to $29 \%)$ in the polyethylene group when compared with the baseline values $(\mathrm{p}<0.001)$.

When testing for factors which might influence the BMD, gender was significant for acetabular zone III and femoral zones 2, 3, 4 and 5 at one week post-operatively and remained so at five years post-operatively (Table I). Age was significantly associated with BMD in femoral zones 6 and 7 at one week post-operatively and remained so at five years
(Table II). The BMI was significantly associated with the BMD in acetabular zone I and in femoral zones 1 and 6 at the beginning and end of the study period (Table III). The diagnosis was significantly associated with the BMD in the immediate post-operative scan in acetabular zone I and in femoral zones 2, 3, 4, 5 and 6 (Table IV).

\section{Discussion}

Although it might be anticipated that more severe stress shielding resulting in bone resorption would occur in the presence of an alumina-on-alumina compared to an alumina-on-polyethylene bearing because of the greater stiffness of the ceramic liner, we found no difference in the changes in the BMD between the groups. We suspect that differences in the modulus of elasticity between aluminaon-alumina and alumina-on-polyethylene bearings, when the acetabular articulating materials were contained within identical titanium metal shells, were insufficient to effect quantitative changes in the BMD between the groups over the five years of the study.

However, when compared with baseline values, significant regional changes in the BMD were detected in all zones of the acetabulum in both groups. There was an increase in 
the BMD adjacent to the prosthetic rim and a decrease in the central pelvic zone. These findings were consistent with the computer simulations reported by Levenston et al. ${ }^{12}$ They suggested that when the acetabulum was loaded medially, the fully-fixed acetabular component transferred most of the load peripherally near the rim, and stress shielding of the medial cancellous bone occurred.

The BMD in acetabular zone III progressively decreased in both groups for three years, but increased to the baseline level at five years. We speculate that initially most of the load was transferred to the acetabular zone I and peripherally near the rim, but with maturation of circumferential bone ingrowth, the acetabular component further stabilised after three years and zone III participated in the transfer of load.

The clinical success of the IPS femoral component has been demonstrated with a survivorship of $100 \%$ at 6.6 years. ${ }^{15}$ In our study we confirmed that this stem transmitted mechanical forces mainly to the proximal one-third of the femur in accordance with the principles of its design. ${ }^{19}$ The mean bone loss five years after surgery at the calcar $(15 \%$ in the alumina group and $14 \%$ in the polyethylene group) and the greater trochanter $(2 \%$ in the alumina group and $3 \%$ in the polyethylene group) was less than that in several other longitudinal reports using designs of stem which were assumed to favour more proximal fixation. ${ }^{4,24,25}$ We believe that the tapered distal stem and close fit of the proximal stem of the IPS prosthesis in the calcar and greater trochanter are contributing factors for the pattern of bone remodelling in the proximal femur.

Previous studies ${ }^{4,26,27}$ reported that the BMD was decreased in femoral zones 2, 3, 4 and 5 up to eight years after surgery. However, Brodner et $\mathrm{al}^{28}$ demonstrated an increase in the BMD in femoral zones 2, 3, 4 and 5 over a five-year period. Our results were consistent with these findings. In addition, we found that male patients had a significantly greater baseline BMD, than females in femoral zones 2, 3, 4 and 5 as well as subsequent intervals. However, the gender differences in BMD were not significant in the more proximal regions of the femur. The immediate post-operative BMD was significantly higher in femoral zones 2, 3, 4, 5 and 6 in patients with osteonecrosis when compared with those with osteoarthritis but this is likely to reflect the younger age and predominance of this diagnosis in males.

In conclusion, our measurements of BMD around acetabular and femoral components after THR for two groups of patients where the only difference was the use of an acetabular liner made of alumina ceramic or UHMWPE, identified no difference in stress-shielding-related bone remodelling of the acetabulum or femur up to five years after operation.

\footnotetext{
The authors would like to acknowledge the help of Sang-Mi-Lee, research associate, for her part in analysing the pelvis and femoral bone scans.

No benefits in any form have been received or will be received from a commercial party related directly or indirectly to the subject of this article.
}

\section{References}

1. Kröger H, Miettinen H, Arnala I, et al. Evaluation of periprosthetic bone using dualenergy-X-ray absorptiometry: precision of the method and effect of operation on bone mineral density. J Bone Miner Res 1996;11:1526-30.

2. Martini F, Sell S, Kremling E, Kusswetter W. Determination of periprosthetic bone density with the DEXA method after implantation of custom-made uncemented femoral stems. Int Orthop 1996;20:218-21.

3. Malchau H, Herberts $\mathbf{P}$, Ahnfelt L. Prognosis of total hip replacement in Sweden: followup of 92,675 operations performed 1978-1990. Acta Orthop Scand 1993;64:497-506.

4. Marchetti MM, Steinberg GG, Greene JM, Jenis LG, Baran DT. A prospective study of proximal femur bone mass following cemented and uncemented hip arthroplasty. J Bone Miner Res 1996;11:1033-9.

5. Markel MM, Gottsauner-Wolf F, Bogdanske JJ, Wahner HW, Chao EY. Dual energy $x$-ray absorptiometry of implanted femora after cemented and press-fit total hip arthroplasty in a canine model. J Orthop Res 1993;11:452-6.

6. Spittlehouse AJ, Smith TW, Eastel R. Bone loss around 2 different types of hip prostheses. J Arthroplasty 1998;13:422-7.

7. Bobyn JD, Mortimer ES, Glassman AH, et al. Producing and avoiding stress shielding: laboratory and clinical observations of noncemented total hip arthroplasty. Clin Orthop 1992:274:79-96.

8. Engh CA, McGovern TF, Bobyn JD, Harris WH. A quantitative evaluation of periprosthetic bone-remodeling after cementless total hip arthroplasty. J Bone Joint Surg [Am] 1992;74-A:1009-20.

9. Kilgus D, Shimaoka EE, Tipton JS, Eberle RW. Dual-energy x-ray absorptiometry measurement of bone mineral density around porous-coated cementless femoral implants: methods and preliminary results. J Bone Joint Surg [Br] 1993;75-B:279-87.

10. McCarthy CK, Steinberg GG, Agren M, et al. Quantifying bone loss from the proximal femur after total hip arthroplasty. J Bone Joint Surg [Br] 1991;73-B:774-8.

11. McGovern TF, Engh CA, Zettle-Schaffer K, Hooten JP Jr. Cortical bone density of the proximal femur following cementless total hip arthroplasty. Clin Orthop 1994;306:145-54.

12. Levenston ME, Beaupre GS, Schurman DJ, Carter DR. Computer simulations of stressrelated bone remodeling around noncemented acetabular component. J Arthroplasty 1993;8:595-605.

13. Sabo D, Reiter A, Simank HG, et al. Periprosthetic mineralization around cementless total hip endoprosthesis: Iongitudinal study and cross-sectional study on titanium threaded acetabular cup and cementless Spotorno stem with DEXA. Calcif Tissue Int 1998;62:177-82.

14. Korovessis P, Piperos G, Michael A. Periprosthetic bone mineral density after Mueller and Zweymullar total hip arthroplasties. Clin Orthop 1994;309:214-21.

15. Kim Y-H, Kim J-S, Oh S-H, Kim J-M. Comparison of porous-coated titanium femoral stems with and without hydroxyapatite coating. J Bone Joint Surg [Am] 2003;85-A:1682-8.

16. Cohen B, Rushton N. Accuracy of DEXA measurement of bone mineral density after total hip arthroplasty. J Bone Joint Surg [Br] 1995;77-B:479-83.

17. Goh JCH, Low SL, Bose K. Effect of femoral rotation on bone mineral density measurements with dual energy $x$-ray absorptiometry. Calcif Tissue Int 1995;57:340-3.

18. Martini F, Lebherz C, Mayer F, et al. Precision of the measurement of periprosthetic bone mineral density in hips with a custom-made femoral stem. J Bone Joint Surg [Br]2000;82B:1065-71.

19. DeLee JG, Charnley J. Radiological demarcation of cemented sockets in total hip replacement. Clin Orthop 1976;121:20-32.

20. Gruen TA, McNeice GM, Amstutz HC. "Modes of failure" of cemented stem-type femoral components: a radiographic analysis of loosening. Clin Orthop 1979;141:17-27.

21. ODR Series. User's guide for $x$-ray bone densitometer with $\mathrm{QDR}$ for Windows. Hologic Inc., Waltham, Massachusetts.

22. Harris WH. Traumatic arthritis of the hip after dislocation and acetabular fractures: treatment by mold arthroplasty: an end-result study using a new method of result evaluation. $J$ Bone Joint Surg [Am] 1969:51-A:737-55.

23. Riffenburgh RH.Tests on mean of continuous data. In Riffenburgh RH, ed. Statistics in medicine. Amsterdam: Elsevier, 2006:305-29.

24. Rosenthall L, Bobyn JD, Brooks CE. Temporal changes of periprosthetic bone density in patients with a modular noncemented femoral prosthesis. J Arthroplasty 1999;14:71-6.

25. Wixson RL, Stulberg SD, Van Flandern GJ, Puri L. Maintenance of proximal bone mass with an uncemented femoral stem: analysis with dual-energy x-ray absorptiometry. J Arthroplasty 1997;12:365-7.

26. Kiralti BJ, Checovich MM, McBeath AA, Wilson MA, Heiner JP. Measurement of bone mineral density by dual energy x-ray absorptiometry in patients with the Wisconsin hip, an uncemented femoral stem. J Arthroplasty 1996;11:184-93.

27. Nakamura K. Measurement of periprosthetic bone mineral density after cementless hip arthroplasty by dual energy x-ray absorptiometry: Iongitudinal and cross-sectional evaluation. J Orthop Sci 1996;1:113-22.

28. Brodner W, Bizan P, Lomoschitz F, et al. Changes in bone mineral density in the proximal femur after cementless total hip arthroplasty: a five-year longitudinal study. J Bone Joint Surg [Br] 2004;86-B:20-6. 